\title{
Student empathy levels across 12 medical and health professions: an interventional study
}

\author{
Brett Williams ${ }^{1 *}$, Ted Brown ${ }^{2}$, Lisa McKenna ${ }^{3}$, Claire Palermo ${ }^{4}$, Prue Morgann ${ }^{5}$, Debra Nestel ${ }^{6}$, Richard Brightwell ${ }^{7}$, \\ Susan Gilbert-Hunt ${ }^{8}$, Karen Stagnitti ${ }^{9}$, Alexander Olaussen ${ }^{1}$ and Caroline Wright $^{10}$
}

\begin{abstract}
Background: Empathy is a difficult characteristic to define, teach and assess; the 'nebulous' properties of empathic behaviour often means that educators fail to incorporate the explicit teaching and assessment of empathy within the curriculum. One solution suggested is that teaching empathy in an interprofessional education setting is an effective educational approach in developing empathic behaviours.

Method: Student participants from Monash University, Deakin University, University of South Australia, and Edith Cowan University completed a self-reporting survey package pre and post two-hour empathy workshop consisting of the Jefferson Scale of Empathy - Health Profession - Student version (JSE-HP-S).
\end{abstract}

Results: A total of 293 students from 12 different medical and health care professions participated in the empathy workshops. The majority of participants were from Monash University $n=230(78 \%)$, the nursing profession $n=59$ $(20 \%),<26$ years of age $n=215(73 \%)$ and enrolled in first year studies $n=123(42 \%)$. Using a paired $t$-test repeated measure self-reported empathy levels improved at $p<0.0001$, mean 114.34 vs. $120.32(d=0.22)$.

Conclusion: This project has shown that self-reported empathy levels have been shown to statistically improve following DVD simulation-based workshops.

Keywords: Empathy, Health Professions, Undergraduate, Curriculum

\section{Background}

Evidence is emerging that clinician empathy improves clinical outcomes [1,2], but diminishes with experience [3-7]. More empathetic clinicians get better results; but more experienced clinicians tend to show less empathy $[1,2]$. These findings suggest both the importance and complexity of empathy in the clinical setting, and raise questions about how empathy can be fostered and maintained to improve clinical outcomes.

Empathy is the ability to understand the experience of others, and to reflect that understanding back to them $[8,9]$. The experience of others may include complex perspectives, reactions and emotions that are not externally visible and that exist in the context of the life of an individual. In lay terms, we could say that empathy is the ability to put oneself into another's shoes, and to demonstrate

\footnotetext{
* Correspondence: brett.williams@monash.edu

'Department of Community Emergency Health and Paramedic Practice, Monash University, Peninsula Campus, McMahons Road, PO Box 527, Frankston, VIC 3199, Australia

Full list of author information is available at the end of the article
}

that one knows what it is like to be in their shoes $[10,11]$. Empathy is often confused with sympathy, but there is an important distinction: empathy is about shared understanding, while sympathy is about shared emotion $[9,12]$. Understanding that another person may be suffering is empathy, whereas actually sharing or experiencing some of their suffering is sympathy. Empathy is cognitive, whereas sympathy is affective [12].

Clinician empathy is a key communication skill that forms a part of patient-centred care; a broad approach to clinical work that has emerged in the past couple of decades and has been formalised and included in many codes of conduct and guidelines published by medical colleges [13-17]. The key principle of patient-centred care is that the clinical process aims to focus on the patient rather than their disease, test results or possible interventions [18]. A clinician undertaking patient-centred care would consider not just if a treatment is available, but whether it is appropriate for the individual patient considering their culture, lifestyle, preferences 
and circumstances [19]. Clearly empathy, as it fosters an understanding of the patient experience, is essential in obtaining this information.

Regardless of whether it is understood or practiced within a framework of patient-centred care, it seems intuitive that empathy can lead to improved clinical outcomes $[1,2]$. A clinician who makes an effort to understand their patient will be more likely to offer advice, treatments and medications that are compatible with the patient's lifestyle and are likely to be followed and used $[20,21]$. This improved compliance can directly affect clinical outcomes.

Indeed evidence has emerged that shows a positive correlation between clinician empathy and improved clinical outcomes. Specifically, diabetic patients have been shown to have better control of blood glucose and lipid levels if they have been seen by a clinician with a higher degree of empathy $[1,2]$. This result was seen in retrospective correlational studies of over 20,000 patients in Italy [2], and 891 patients in the United States [1]. While more studies are needed to show if these results will hold with different health professions, patient groups and different clinical conditions, the high number of patients in these studies, the different cultural settings, and the complexity involved in managing diabetes suggest that the effect of empathy on clinical outcomes is clear.

There is evidence that the skills required for patientcentred care, and more specifically for empathy as a learned behaviour, can be taught and maintained with training programmes lasting as short as one hour [22, 23]. However, whether such short interventions lead to improved clinical outcomes, and whether those outcomes can be sustained, is less clear. Evidence has shown that more experienced clinicians and students closer to graduation tend to show less empathy $[4,7,24]$. It would therefore be especially helpful to work toward a brief and convenient means of education and training for and sustaining levels of empathy that would be compatible with the life of a working clinical practitioner and for the progressing student.

In this study we aim to evaluate the effectiveness of a DVD simulation-based workshop in improving self-reported empathy in tertiary healthcare students.

\section{Method}

\section{Design}

This study employed a before and after study repeated measures design.

\section{Workshop design and delivery}

During August and September a two-hour interactive empathy workshop was delivered to undergraduate medical and health professional students at four Australian universities: Monash University, Deakin University, University of South Australia and Edith Cowan University.
The empathy workshops were interprofessional (with a minimum of three different health professional groups participating in each workshop), interactive and based around a 20-min DVD simulation involving either: i) Teenager diagnosed with asperger's syndrome, ii) Young pregnant female suffering a stroke, and iii) An elderly indigenous lady suffers a suspected neck of femur fracture. Each DVD included a patient journey involving the following professions: paramedics, nursing, medicine, midwifery, radiography, physiotherapy, occupational therapy and nutrition and dietitics. Activities were based on small group work and group presentations. Participants examined the medical definitions of empathy and the vernacular of empathy versus other terms such as sympathy, affinity, caring etc. Participants were also asked to focus on empathy and consider four questions as they watched the DVD: (i) What do you think the needs of the patient/client are? (ii) Do you think the patients'clients' needs were met in the clinical interaction? (iii) What empathetic behaviours did you see or observe during the scenario? (iv) And what was the impact of this behaviour on the patient interaction as they watch one of the DVDs. A number of short (3 min) interviews with clinicians were also shown outlining why each clinician believed empathy was important for health care management. The delivery of each workshop was undertaken by BW and professional facilitator. (For more details see: http://med.monash.edu.au/cehpp/altcempathy/).

\section{Participants}

Potential students were enrolled in all year levels (1st to 5th year) at one of the aforementioned universities using convenience sampling. Given the nature of sampling across multiple universities and courses we were unable to calculate a response rate. Inclusion criteria for the study were being enrolled in a medical or health care professional program. Each university academic lead recruited students via flyers, information sessions, and emails during July and August 2012. Names and emails were collected and contacted prior to workshops taking place. Workshops took place during the academic teaching semester and at each university. All workshop participants were provided with a certificate of attendance.

\section{Instrumentation}

The study used a standardised self-reporting scale: Jefferson Scale of Empathy - Health Profession - Student version (JSE-HP-S) which is a self-report measure of health profession students' attitudes towards empathy. It is a 20 -item scale that uses a 7-point Likert-scale $(1=$ strongly disagree and $7=$ strongly agree) with 10 items reversed scored. The JSE-HP-S is both valid and reliable [25, 26]. A short demographic questionnaire was also included. 


\section{Procedures}

Prior to the empathy workshop students were invited to participate on a voluntary basis in this study. Students were provided with an explanatory statement and were informed that participation was voluntary and matched by identification for follow-up. The questionnaires took students approximately $10 \mathrm{~min}$ to complete and consent was implied by its completion and submission. The follow-up took place six weeks later; again students were informed of the study and asked to complete the follow-up questionnaire.

\section{Data analysis}

The SPSS program (Statistical Package for the Social Sciences Version 20.0, SPSS Inc., Chicago, Illinois, U.S.A.) was used for data storage, tabulation, and the generation of descriptive and inferential statistics. Descriptive statistics means and standard deviations (SD) were used to summarise the demographic data. A paired $t$-test for repeated measures was used to compare before and after results, while a combination of parametric and nonparametric tests were used in cases of non-normally distributed data. All tests were two tailed with the results considered statistically significance if the $p$ value is $<0.05$; effect sizes $(d)$ were also calculated for quantifying the differences between mean scores.

\section{Results}

\section{Participant demographics}

A total of 293 students from 12 different medical and health care professions participated in the workshops in between July and September 2012. The majority of participants studied at Monash University $n=230$ (78 \%). The most frequently represented profession was nursing $(n=59,20 \%)$, closely followed by paramedics $(n=55$, $19 \%)$ and dietetics $(n=47,16 \%) .73 \%$ of the cohort were aged younger than 26 years $(n=215)$, and $42 \%$ were enrolled in their first year of studies $(n=123)$. For further details on the demographics, see Table 1.

The mean JSE-HP-S score for all of the participants prior to the intervention was 114.39 (SD =14.56). After the intervention a statistically significant improvement was observed $120.56(\mathrm{SD}=12.48 ; \mathrm{p}<0.0001)$ with a small effect size $(d=0.22)$.

In our study we found that females had a higher mean score both pre and post intervention, increasing from 116 to $126(p=0.008)$. The male students scored significantly lower both pre and post intervention, although they also showed an improvement following the intervention (from 113 to $120, p=0.037$ ).

Regarding the students year level we noted a statistically significant difference between the groups prior to intervention $(p=0.004)$. There was a decline in the level of empathy from year 1 (JSE-HP-S $=115$ ) to year 5 (JSEHP-S =101.5). No statistical differences were found between
Table 1 Participant demographics

\begin{tabular}{|c|c|c|c|}
\hline Variable & Descriptor & Frequency & Percentage \\
\hline \multirow[t]{2}{*}{ Gender } & Female & 226 & 77.1 \\
\hline & Male & 67 & 22.9 \\
\hline \multirow[t]{4}{*}{ University } & Monash & 230 & 78.5 \\
\hline & ECU & 38 & 13.0 \\
\hline & UniSA & 23 & 7.8 \\
\hline & Deakin & 2 & 0.7 \\
\hline \multirow[t]{12}{*}{ Student course } & Nursing & 59 & 20.1 \\
\hline & Paramedic & 55 & 18.8 \\
\hline & Dietetics & 47 & 16 \\
\hline & Occupational Therapy & 29 & 9.9 \\
\hline & Nursing/paramedics & 27 & 9.2 \\
\hline & Medicine & 18 & 6.1 \\
\hline & Radiography & 17 & 5.8 \\
\hline & Radiation therapy & 14 & 4.8 \\
\hline & Midwifery & 11 & 3.8 \\
\hline & Physiotherapy & 8 & 2.7 \\
\hline & Biomedical & 5 & 1.7 \\
\hline & Podiatry & 3 & 1 \\
\hline \multirow[t]{5}{*}{ Year level } & Year 1 & 123 & 42.0 \\
\hline & Year 2 & 81 & 27.6 \\
\hline & Year 3 & 54 & 18.4 \\
\hline & Year 4 & 27 & 9.2 \\
\hline & Year 5 & 8 & 2.7 \\
\hline
\end{tabular}

the groups after the intervention $(p=0.847)$. No statistically significant differences were found between age groups.

Interestingly, comparing the different courses yielded significant differences. The students enrolled in midwifery had the highest pre intervention score (JSE-HP-S $=124$ ). The lowest scoring courses were radiography and biomedical science (JSE-HP-S $=104$, and 101 respectively). However, these two groups were the ones experiencing the most significant improvement (biomedicine by a mean = 13 and radiography by a mean $=14$ ). The groups with the least mean score improvements were: midwifery, medicine, and the double degree nursing/paramedic. No groups experienced a reduction in mean scores.

\section{Discussion}

This before and after repeated measures study found that self-reported empathy scores of undergraduate health profession students significantly improve after participation in a DVD simulation-based empathy workshop. These results strengthen previous findings suggesting that empathy can be taught using various educational activities and interventions [22, 27]. Given that empathy has shown to improve clinical outcomes, and can be taught or fostered 
quickly and cost effectively, these results should add weight to the argument of incorporating empathy training in undergraduate and even ongoing professional education for healthcare workers.

Of particular interest in our study is that improvements in empathy were seen across a range of health professions. Students enrolled in biomedical science, radiography, radiation therapy demonstrated the greatest benefits of this intervention. A review of the literature revealed no studies to explain or expand on this finding. A possible answer might be that since these health care specialities have limited patient interaction compared to other courses has, i) less focus on empathy education, and ii) attracts students who are naturally less inclined towards empathetic behaviour.

We also found that both paramedic students and nursing students had a similarly large benefit of the intervention (a mean score improvement of 12). Given that these are more patient-oriented specialties such results were positive. The fact that the double degree in comparison experienced no improvements remains unclear. The DVD intervention did not reduce any student's empathy score, a finding which is consistent with all other interventional empathy education studies [22]. Whether such interventions can have long-lasting impact on self-reported empathy levels remains a key question for researchers, and indeed whether such interventions can effect decline in empathy levels, although recent work in this area by Roff may suggest otherwise [24].

Previous studies have found that doctors and nurses show similar levels of empathy [28]. This is inconsistent with our findings when comparing medical students and nursing students. We found that pre intervention medical students scored higher than nursing students (116.5 versus 113). However in contrast post intervention the nursing students scored higher (125 versus 118).

There is agreement in the literature that females show greater levels of empathy than males [3, 5, 29-41]. This is consistent with our findings that found that both groups were amendable to empathy education, but females slightly more (116 to 126 versus 113 to $120, p=0.037$ post intervention) Winefield and Chur-Hansen [42] studied 107 first year medical students and tested empathy levels prior to didactic teaching, videotapes and 3 hour of workshops with actors as patients. Although this study did not use the JSEHP-S, their observed improvement in empathy levels, and that females improve the most is consistent with our findings. In contrast, it should be noted that there are reported studies where a gender difference is not observed [43-46], and warnings that this has little real-life applicability [39].

While empathy is clearly a complex quality that may exist at different levels in different professions and with different levels of experience, our data suggests that it is not too complex to be amenable to education, particularly education that is interprofessional in nature, and that the intervention required to achieve these goals does not need to be costly or time consuming. For empathy education to be most effective, and not be felt as an "add-on", it has been argued that it must not be separate out to the biomedical components of medicine, but rather integrated [47].

The intervention used in this study was DVD-based, and as such an empathy-based learning package could be easily delivered to students and healthcare professionals in multiple educational settings. It would also be possible that an online version could be developed and distributed without little or no per-unit publishing cost. This combined with the ability for participants to use a DVD or online learning tool in their own time, make the learning package very practical and sustainable. An online version could also incorporate opportunities for participants to engage in discussion forums or provide feedback. Further examination of this will be explored in future project work.

A large body of work has found that empathy tends to erode with time, speciality and or professional experience $[4,7]$. While the question of empathy maintenance was not specifically addressed in our study, we did not find lower JSE-HP-S scores in the students closer to their final year. It will be useful and interesting to see whether our intervention could be used to sustain or renew empathy in experienced practitioners.

\section{Limitations}

The study had a number of limitations. Firstly, our study was only conducted in Australia using undergraduate university student subjects. Secondly, while we used a well-established self-report measure, it still brings with it inherent reporter biases. While changes to attitudes following the workshops, we were unable to measure if these attitudinal changes positively impacted on patient and/or client care. Results may not translate to subjects who are in the workplace and experiencing patientmanagement and clinical challenges on a day-to-day basis. Another limitation was the length of the workshop, and a lack of randomisation of participants. We did not evaluate the students' change in empathy levels beyond the six weeks; this is provides opportunities for further research both in terms of curricula innovations but also changes to organisational culture.

\section{Conclusion}

A simple DVD-based learning package can be used to teach and possibly to sustain empathy levels in healthcare workers from a range of professions. As empathy has been shown to improve clinical outcomes, this finding suggests that empathy training is a low-cost means of achieving 
improved clinical outcomes in a variety of healthcare settings. This project has provided important information in informing the development of medical and health care curricula that are directly responsive to the requirements of contemporary healthcare in Australia.

\section{Competing interests}

The authors declare that they have no competing interests.

\section{Authors' contributions}

$B W, T B, L M, C P, D N, R B, S G H, K S$ all developed study idea. BW, AO, LM, DN, CP performed data collection and data analysis. BW performed statistical analysis. $B W$ and $A O$ drafted manuscript with contributions from $T B, L M, C P$, $\mathrm{DN}, \mathrm{RB}, \mathrm{SGH}, \mathrm{KS}, \mathrm{CW}$. All authors read and approved final manuscript.

\section{Acknowledgements}

We would like to thank the students who participated in the workshops. We would acknowledge the funding support provided by the Office for Learning and Teaching, Australian Government.

\section{Author details}

'Department of Community Emergency Health and Paramedic Practice, Monash University, Peninsula Campus, McMahons Road, PO Box 527, Frankston, VIC 3199, Australia. ${ }^{2}$ Department of Occupational Therapy, Monash University, Victoria, Australia. ${ }^{3}$ School of Nursing and Midwifery, Monash University, Victoria, Australia. ${ }^{4}$ Department of Nutrition and Dietitics, Monash University, Victoria, Australia. ${ }^{5}$ Department of Physiotherapy, Monash University, Victoria, Australia. ${ }^{6}$ Rural Medical School, Monash University, Victoria, Australia. 'Department of Paramedics, Edith Cowan University, Perth, Australia. ${ }^{8}$ Department of Occupational Therapy, University of South Australia, Adelaide, Australia. ${ }^{9}$ Department of Occupational Therapy, Deakin University, Victoria, Australia. ${ }^{10}$ Department of Medical Imaging and Radiation Sciences, Monash University, Victoria, Australia.

Received: 9 November 2014 Accepted: 27 May 2015

Published online: 06 June 2015

\section{References}

1. Hojat M, Louis DZ, Markham FW, Wender R, Rabinowitz C, Gonnella JS. Physicians' empathy and clinical outcomes for diabetic patients. Acad Med. 2011;86:359-64.

2. Del Canale S, Louis DZ, Maio V, Wang X, Rossi G, Hojat M, et al. The relationship between physician empathy and disease complications: an empirical study of primary care physicians and their diabetic patients in Parma, Italy. Acad Med. 2012;87:1243-9.

3. Sherman JJ, Cramer A. Measurement of changes in empathy during dental school. J Dental Educ. 2005;69:338-45.

4. Hojat M, Mangione S, Nasca TJ, Rattner S, Erdmann JB, Gonnella JS, Magee M. An empirical study of decline in empathy in medical school. In: Medical Education. vol. 38: Blackwell Science Ltd; 2004: 934-941.

5. Nunes P, Williams $S$, Sa B, Stevenson K. A study of empathy decline in students from five health disciplines during their first year of training. Int J Med Educ. 2011;2:12-7.

6. Ward J, Cody J, Schaal M, Hojat M. The empathy enigma: an empirical study of decline in empathy among undergraduate nursing students. J Prof Nurs. 2012;28:34.

7. Neumann M, Edelhäuser F, Tauschel D, Fischer MR, Wirtz M, Woopen C, et al. Empathy decline and its reasons: a systematic review of studies with medical students and residents. Acad Med. 2011;86:996-1009.

8. Looi JCL. Empathy and competence. MJA. 2008;188:414-6.

9. Hojat M, Gonnella JS, Nasca TJ, Mangione S, Vergare M, Magee M. Physician empathy: definition, components, measurement, and relationship to gender and specialty. Am J Psychiatry. 2002;159:1563-9.

10. Ahrweiler F, Neumann M, Goldblatt H, Hahn E, Scheffer C. Determinants of physician empathy during medical education: hypothetical conclusions from an exploratory qualitative survey of practicing physicians. BMC Med Educ. 2014;14:122.

11. Williams B, Brown T, McKenna L, Boyle M, Palermo C, Nestel D, et al. Empathy levels among health professional students: a cross-sectional study at two universities in Australia. Advances Med Educ Practice. 2014;5:107-13.
12. Raines J. Empathy in clinical social work. In: Clinical Social Work Journal. vol. 18: Kluwer Academic Publishers-Human Sciences Press; 1990: 57-72.

13. Makoul G, Schofield T. Communication teaching and assessment in medical education: an international consensus statement. Patient Educ Counsel. 1999;37:191-5

14. AMA Code of Ethics - 2006. Editorially Revised 2006 [http://www.amsws. org.au/media/docs/images/ama_code_of_ethics.pdf]

15. Good Medical Practice: a code of conduct for doctors in Australia [http:// www.medicalboard.gov.au]

16. Brown J. How clinical communication has become a core part of medical education in the UK. In: Medical Education. vol. 42: Blackwell Publishing Ltd; 2008: $271-278$.

17. Hollands MJ. Providing non-technical skills for surgeons. Can non-technical competencies be learnt in the context of a scientific conference? MJA. 2013;198:400.

18. Stewart M. Towards a global definition of patient centred care. Br Med J. 2001;322(7284):444-5.

19. Williams B, Sadasivan S, Kadirvelu A, Olaussen A. Empathy levels among first year Malaysian medical students: an observational study. Advances Med Educ Practice. 2014;5:149-56.

20. Pettinati HM, Volpicelli JR, Pierce Jr JD, O'Brien CP. Improving naltrexone response: an intervention for medical practitioners to enhance medication compliance in alcohol dependent patients. J Addict Dis. 2000;19(1):71-83.

21. Vermeire E, Hearnshaw H, Van Royen P, Denekens J. Patient adherence to treatment: three decades of research. A comprehensive review. J Clin Pharmacy Therapeutics. 2001;26(5):331-42.

22. Stepien KA, Baernstein A. Educating for empathy. Rev J General Internal Med. 2006;21(5):524-30.

23. Guastello S, Frampton S. Patient-centered care retreats as a method for enhancing and sustaining compassion in action in healthcare settings. J Compassion Health Care. 2014;1:2.

24. Roff S. Reconsidering the "decline" of medical student empathy as reported in studies using the Jefferson Scale of Physician Empathy-Student version (JSPE-S). Medical Teacher 2015, 1-4(Early Online).

25. Fields SK, Mahan P, Tillman P, Harris J, Maxwell K, Hojat M. Measuring empathy in healthcare profession students using the Jefferson Scale of Physician Empathy: health provider-student version. J Interprof Care. 2011;25(4):287-93.

26. Williams B, Brown T, Boyle M, Dousek S. Psychometric testing of the Jefferson scale of empathy health profession Students' version with Australian paramedic students. Nursing Health Sciences. 2013;15(1):45-50.

27. Dwamena F, Holmes-Rovner M, Gaulden CM, Jorgenson S, Sadigh G, Sikorskii A, Lewin S, Smith RC, Coffey J, Olomu A. Interventions for providers to promote a patient-centred approach in clinical consultations. In: Cochrane Database of Systematic Reviews. 2012.

28. Fields SK, Hojat M, Gonnella JS, Mangione S, Kane G, Magee M. Comparisons of nurses and physicians on an operational measure of empathy. Evaluation Health Professions. 2004;27:80-94.

29. Williams CA. Empathy and burnout in male and female helping professionals. Res Nursing Health. 1989;12:169-78.

30. Sleath B, Carpenter DM, Slota C, Williams D, Tudor G, Yeatts K, et al. Communication during pediatric asthma visits and self-reported asthma medication adherence. Pediatrics. 2012;130:627-33.

31. Chen DC, Kirshenbaum DS, Yan J, Kirshenbaum E, Aseltine RH. Characterizing changes in student empathy throughout medical school. Med Teacher. 2012;34(4):305-11.

32. Di Lillo M, Cicchetti A, Lo Scalzo A, Taroni F, Hojat M. The Jefferson scale of physician empathy: preliminary psychometrics and group comparisons in Italian physicians. Acad Med J Assoc Am Med Colleges. 2009;84(9):1198-202.

33. Fernández-Olano C, Montoya-Fernández J, Salinas-Sánchez AS. Impact of clinical interview training on the empathy level of medical students and medical residents. Med Teacher. 2008;30(3):322-4.

34. Hojat M. Empathy in patient care : antecedents, development, measurement, and outcomes. New York, NY: Springer; 2007.

35. Hojat M, Gonnella J, Mangione $\mathrm{S}$, et al. The Jefferson scale of physician empathy: development and preliminary psychometric data. Educ Psychol Meas. 2001;61:349-65.

36. Hojat M, Vergare MJ, Maxwell K, Brainard G, Herrine SK, Isenberg GA, et al. The devil is in the third year: a longitudinal study of erosion of empathy in medical school. Acad Med J Assoc Am Med Colleges. 2009;84(9):1182-91. 
37. Kataoka H, Koide N, Ochi K, Hojat M, CGonnella J. Measurement of empathy among Japanese medical students: psychometrics and score differences by gender and level of medical education. Acad Med. 2009;84(9):1192-7.

38. Magalhaes E, Salgueira AP, Costa P, Costa MJ. Empathy in senior year and first year medical students: a cross-sectional study. BMC Med Educ. 2011;11:52.

39. Rahimi-Madiseh M, Tavakol M, Dennick R, Nasiri J. Empathy in Iranian medical students: a preliminary psychometric analysis and differences by gender and year of medical school. Med Teacher. 2010;32(11):e471-8.

40. Shariat SV, Habibi M. Empathy in Iranian medical students: measurement model of the Jefferson scale of empathy. Med Teacher. 2013;35(1):e913-8.

41. Ward J, Schaal M, Sullivan J, Bowen ME, Erdmann JB, Hojat M. Reliability and validity of the Jefferson scale of empathy in undergraduate nursing students. J Nurs Meas. 2009;17(1):73-88.

42. Winefield $\mathrm{H}$, Chur-Hansen A. Evaluating the outcome of communication skil teaching for entry-level medical students: does knowledge of empathy increase? Med Educ. 2000;34:90-4.

43. Kliszcz J, Nowicka-Sauer K, Trzeciak B, Nowak P, Sadowska A. Empathy in health care providers - validation study of the Polish version of the Jefferson Scale of Empathy. Advances Med Sci. 2006;51:219-25.

44. Paro H, Daud Gallotti R, Tibério I, Pinto R, Martin M. Brazilian version of the Jefferson scale of empathy: psychometric properties and factor analysis. BMC Med Educ. 2012;12:73.

45. Roh MS, Hahm BJ, Lee DH, Suh DH. Evaluation of empathy among Korean medical students: a cross-sectional study using the Korean Version of the Jefferson Scale of Physician Empathy. Teaching Learn Med. 2010;22(3):167-71.

46. Penprase B, Oakley B, Ternes R, Driscoll D. Do Higher Dispositions for Empathy Predispose Males Toward Careers in Nursing? A Descriptive Correlational Design. Nursing Forum 2014 (early online).

47. Pedersen R. Empathy development in medical education-a critical review. Med Teacher. 2010;32(7):593-600.

\section{Submit your next manuscript to BioMed Central and take full advantage of:}

- Convenient online submission

- Thorough peer review

- No space constraints or color figure charges

- Immediate publication on acceptance

- Inclusion in PubMed, CAS, Scopus and Google Scholar

- Research which is freely available for redistribution 